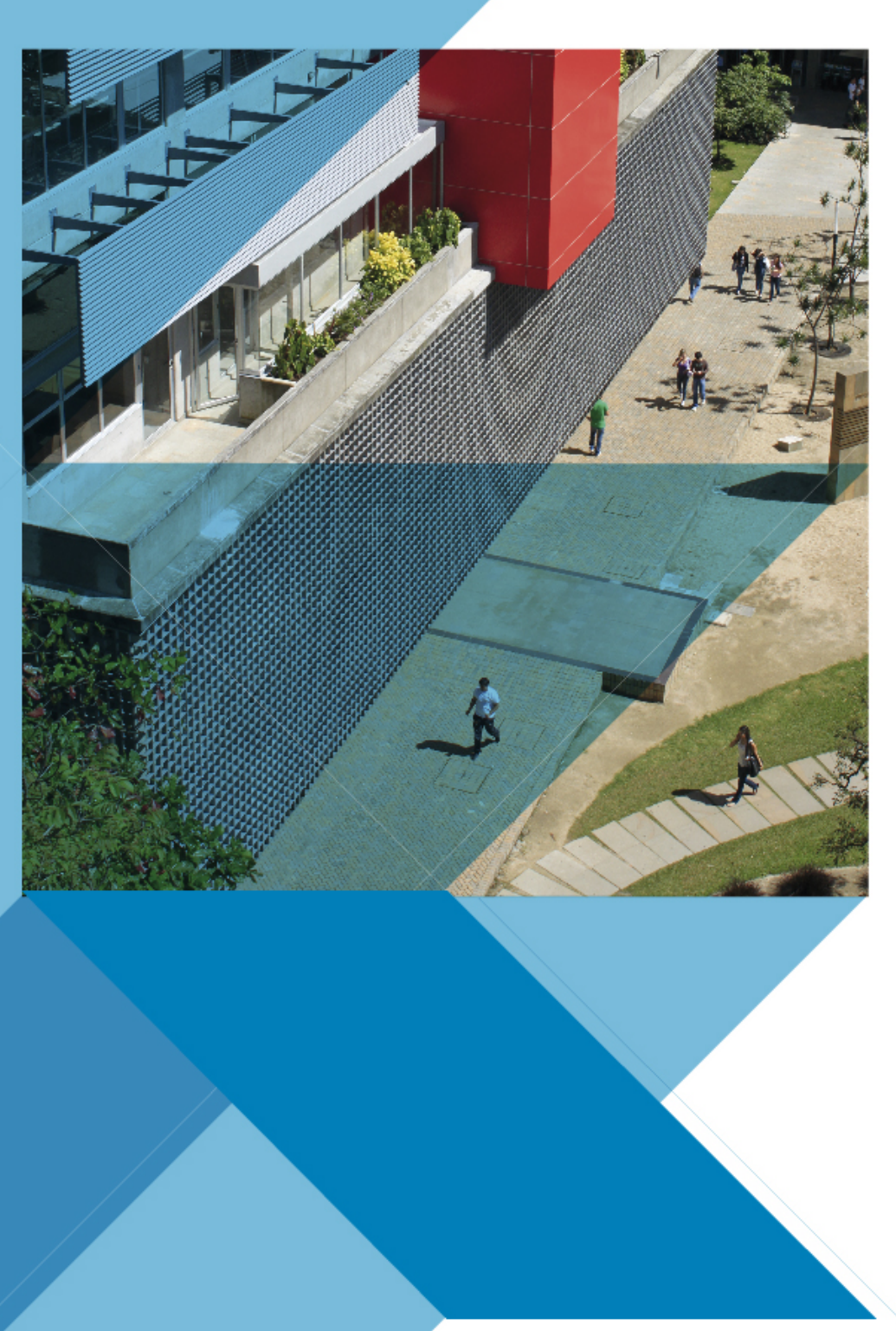

Escuela de Economía y Finanzas

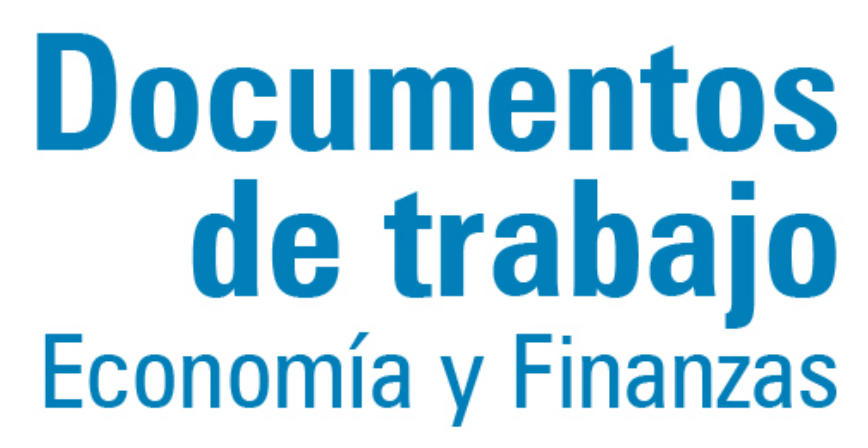

Centro de Investigación Económicas y Financieras

No. 14-06

Informality and formality: Fiscal policy in DSGE model

Botero, Jesús; Vargas, Christian; Hurtado, Álvaro; Franco, Humberto 


\title{
INFORMALITY AND FORMALITY: FISCAL POLICY IN DSGE MODEL.*
}

\author{
Jesús Botero G..$^{\dagger} \quad$ Christian Vargas ${ }^{\ddagger} \quad$ Álvaro Hurtado Rendón ${ }^{\S}$ \\ Humberto Franco
}

March 11, 2014

\begin{abstract}
We develop a DSGE model of the Colombian economy to assess the effect of tax policy on informal employment and income distribution. The model recreates a small open economy, with persistent income inequality, a substantial degree of informality, and different possibilities of government intervention. This paper evaluates the consequences of government transfer payments to households with lower incomes. We find that although transfer payments have a positive effect on income distribution, financing them requires an adjustment in government finances (cut spending or increase revenue through the use of various taxes), which have negative effects on the economic as a whole.
\end{abstract}

JEL Classification: E62, D58.

Keywords:Public expenditure, exogenous shock, DSGE.

${ }^{*}$ We thank Michael Jetter and Gustavo J. Canavire Bacarreza for fruitful comments and discussions. Also, we thank the EAFIT University for supporting the project. Paper presented at 18th conference anual de Latin American and Caribbean Economic Association (LACEA), México D.F. (México), November 2013. All remaining errors are our own.

${ }^{\dagger}$ Department of Economics, Universidad EAFIT, Medellin, Colombia; email: jabotero@eafit.edu.co

${ }^{\ddagger}$ Department of Economics, Universidad EAFIT, Medellin, Colombia; email: cvargas3@eafit.edu.co

$\S$ Department of Economics, Universidad EAFIT, Medellin, Colombia; email: ahurtad1@eafit.edu.co

`Department of Economics, Universidad EAFIT, Medellin, Colombia; email: hfranco@eafit.edu.co 


\section{Introduction}

Efficiency and flexibility are the fundamental elements in the labor market in order to guarantee an effective use of resources. Therefore, markets need to provide conditions, which allow the exchange of workers in a well-organized fashion without incurring substantial costs. Efficient labor markets should bring out the clear relationship between the workers' incentives and their efforts (Competitividad, 2012). The informal sector - under which we usually understand jobs carried out in dubious environments, typically characterized by low productivity, minimal remuneration levels, and hardly any social security - quite possibly poses one of the biggest threats in today's world, especially in the developing economies and the poorest nations on earth. In order to implement political and social policies addressing these issues, it is worthwhile to be as precise as possible in assessing and quantifying the informal sector in its complexity, taking into account the different positions on the topic.

In fact, the respective literature suggests measuring the informal sector quantitatively (e.g. workers per company) as well as qualitatively (e.g. legal registration of the company in corresponding cases). Thus, one faces situations in which measuring informality does not always lead to a definite consensus.

Despite the lack of consensus, it is relatively clear that the informal sector is often associated with working in small family-lead businesses or companies with less than ten workers, whose financial conditions do not permit the delivery of adequate social security coverage (Perry and SaavedraChanduvi (2007)). The definition accepted on the broadest level comes from the International Labour Organization (ILO, 1972) in its employment program, which led to the development of

numerous labor market studies in developing countries in the early 1970s, later formalized by Castells and Belton (1989). In particular, this program classifies productive activities (labours) as part of the informal sector, which generate non-regulated income that ignore obligations such as paying taxes, social security contributions, and complying with minimum wage regulations (Pratap and Quintin, 2006, p. 3).

Further, Schneider and Enste (2000) address common guidelines in measuring the informal 
sector, specifically distinguishing between direct ways of measuring (supported by information obtained from household and small business surveys) and indirect ways (founded in monitoring macroeconomic variables - such as output gaps characterizing business cycles - and econometric modeling techniques $)^{1}$. In averaging various ways of measuring, they conclude the magnitude of the informal sector to vary between 8 and 23 percent in advanced economies, yet the estimated range in developing nations ranges between 23 and 60 percent.

In fact, Colombia provides a good example for a developing country with a sizeable informal sector. The percentage of workers in the informal sector across its 13 biggest cities (measured by the amount of informal employees as a fraction of the entire employed labor force) reaches 62 percent after the recession in the late 1990s, after fluctuating around an average of 55 percent throughout the entire decade. Subsequently, these values are only slightly lower and remain around 56 percent in 2008 and increase again in 2009 towards a considerable 56.2 percent, therefore surpassing the regional average (Crédito Público, 2011)2. But, Hamann and Mejía (2011) confirms, the majority of empirical studies in Colombia suggest that the high degree of informality (in context of the labor market as well as in business), measured as non-reported and non-regulated employment, fluctuates around 60 and 75 percent. It is important to note that business sector informality is based on company size and legal registration. Of course, this scenario calls for the implementation of institutional measures if one wants to address the problem.

This article explores the relationship between informal employment, income distribution, and tax policy from the perspective of a Dynamic Stochastic Equilibrium Model (DSGE), representing a simplified version of the Colombian economy. We consider two distinct types of households: (i) households in the upper half of income, characterized by their access to the financial sector

\footnotetext{
${ }^{1}$ Regarding the information obtained through direct home surveys it is necessary to clarify the following: It is a valuable expression for determining the level of informality in a country (through positions on non-compliance with the law regarding employee benefits, tax statements on tax issues, and accessibility to the financial sector, which can be one of the key determinants of informality). However, the subjective nature of the answers given to the questionnaire cannot be ignored, in which case the measurement of the problem can be imprecise

${ }^{2}$ In the informal employment considered here, we find private employees, workers in small establishments employing no more than five people including the employer or partner, family workers receiving no remuneration, workers in businesses not receiving income in other households, domestic employees, day laborers, self-employed people working in small companies with under five employees. Further, this definition does not contain independent professionals, employers in small companies with up to five workers, and government employees.
} 
and the capacity to accumulate capital and (ii) households in the lower half of income, which are described by liquidity constraints owed to their limited credit access. The model (a) explores the effect of various types of taxes and contributions on informality, and (b) analyzes the consequences of tax burden and subsidy schemes on income distribution. The article proceeds with a brief review of the respective literature in section two and a thorough presentation of the DSGE model of the real economy in section three. Section four contains our simulations and section five concludes.

Our main contribution with this paper is based on the ability to view which of the instruments of fiscal policy is more effective in reducing informality levels of middle-income countries and propose tools to reduce this problem with lower costs on welfare.

\section{The Various Links of Informality}

There exists an extensive literature on informality, which establishes various relationships, such as its connection to poverty, productivity, or external shocks. For instance, the seminal works of Merz (1995), Andolfatto (1996), and Haan and Watson (2000) introduce the concept of an equilibrium unemployment rate in real-business-cycle models in a general way. Further, there exists a strand of literature incorporating labor market frictions into dynamics of inflation, such as Walsh (2005), Krause and Lubik (2007), and Christoffel and Linzert (2010) among others.

In the connection between informality and poverty, Agénor and Dc (2003) uses the MiniIntegrated Macroeconomic Model for Poverty Analysis (IMMPA), developed by Agénor, Izquierdo, and Fofack (2003). Agénor, Fernandes, Haddad, and van der Mensbrugghe (2003) ${ }^{3}$ evaluate the effects of fiscal policy and labor market reforms on employment and poverty, concluding that the effect of these policies depends on how they are financed ${ }^{4}$. However, Alm and López (2002) use

\footnotetext{
${ }^{3}$ Cited by Agénor and Dc (2003).

${ }^{4}$ Policies directed towards the reduction of unemployment can lead to an increase in poverty if the fiscal restrictions impose changes in funding. For instance, compensation in terms of a reduction of transfer payments have negative effects on the poor. Taxes on consumption can have negative effects on the consumption basket of the poor, reducing real income. A reduction of government spending on infrastructure can have harmful effects on global productivity and further an indirect negative impact on private investment levels.
} 
a computable General Equilibrium Model (static) to reach a different conclusion: a reduction of nine percentage points of tax-related variables generates a decrease of one percent in the informal sector labor market and an increase of three percent in the formal sector labor market, which seems to be more in line with observations in reality.

Another area, which has received attention in this context, is the connection between external shocks and the labor market. Specifically, Cook (2005) considers the effect of financial crises on the informal sector, using a DSGE model incorporating search and matching. They find that an external shock to the financial sector can lead to a reallocation from the formal towards the informal sector labor force, in particular towards low-productivity sectors, such as the agricultural sector. In this argument, the external shock on interest rates drives a reduction in the income gap between the agricultural sector and urban workers, particularly for Indonesia. However, Gertler, Gilchrist, and Natalucci (2003) and Meza and Quintín (2005) ${ }^{5}$ argue that the lowered use of factors mostly explains the decrease in labor productivity levels during financial crises in emerging markets.

With respect to developing countries and their relationship to institutions, one may look at the work by Ulyssea (2010) about Brazil, analyzing the effect of various labor market institutions and entry regulations prevailing in the formal sector on the size of the informal sector. The results indicate that the best approach to reduce the size of the informal sector is adopting policies, which reduce the costs of being formal and create the right incentives for companies and workers intending to switch to the formal sector.

On the other hand, raising the costs of being informal reduces informality. This fact is consistent with the findings from Bosch and Esteban-Pretel (2012), who use a DSGE model for Brazil. They employ a labor market split in two sectors with search and matching, where firms decide whether to hire their labor force formally or informally. In this framework, they analyze the effects of changes in public policies on employment and the role of informality in the Brazilian economy. Their findings suggest that the effect of government intervention on the labor market depends on the magnitude of worker reallocation in both the formal and informal sectors. Policies lowering

\footnotetext{
${ }^{5}$ Cited by Cook (2005)
} 
the costs of formality or raising the costs of informality increase the participation rate in the formal sector, while reducing unemployment ${ }^{6}$. This fact is corroborated by Satchi and Temple (2009), who suggest that labor market institutions can have substantial effects in countries with medium incomes, but the effects may not be the same in poorer countries, where a more complex approach might be more likely to succeed.

In the case of Colombia, a country with a medium average income according to the World Bank, Hamann and Mejía (2011) uses a DSGE model to analyze the effect of policies on informality. The remainder of this paper will address this approach, as our exercises concern impact evaluation of increasing transfer payments to constrained households, financed by adjustments in other variables: public spending, taxes on capital, taxes on labor, social security payments, or tariffs. We aim to determine the efficiency of the above transfers, while assessing the impact of the tax instruments available to the government. To this end, we define two main variables: the share of households with constrained income in the total amount of households (a redistributive indicator) and the percentage of informality in the economy (an indicator of efficiency for the use of resources). The various alternatives are evaluated in terms of these variables, in order to determine their efficiency.

\section{The model}

Our model considers two distinct types of households: (1) households with access to credit and financial markets (optimizing households) and (2) liquidity constrained households (restricted households). Having an endowment of skilled and unskilled labor, each household maximizes its utility in deciding over the optimal supply of labor (the first group in an intertemporal context and the latter group makes its decision for the current period).

\footnotetext{
${ }^{6} \mathrm{~A}$ decrease in hiring costs or in taxes on labor income raise the size of the formal sector.
} 


\subsection{Optimizing Households}

The decision faced by a representative optimizing household will be to maximize the future expected value of its utility over time:

$$
\operatorname{Max} E_{t} \sum_{t=0}^{\infty} \beta^{t} \frac{L_{t}}{L_{0}}\left(\operatorname{lnco}_{t}+\psi_{\text {oc }} \ln \left(\text { ppoc }_{t}-\text { noc }_{t}\right)+\psi_{\text {onc }} \ln \left(\text { pponc }_{t}-\text { nonc }_{t}\right)\right),
$$

subject to

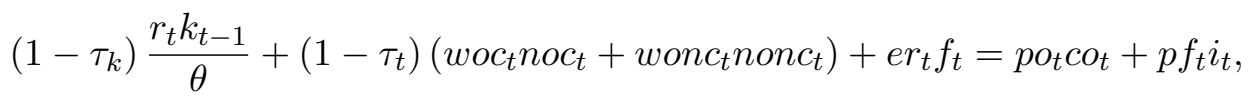

where $\mathrm{co}_{t}$ stand for optimizing household consumption, ppoc $_{t}$ and pponc $_{t}$ are fraction of skilled and non-skilled agents, $n o c_{t}$ and $n o n c_{t}$ are employment of skilled and non-skilled, $r_{t}$ is return of capital, $k_{t-1}$ is capital, $w o c_{t}$ and $w o n c_{t}$ are wage of skilled and non-skilled, $e r_{t}$ is nominal exchange rate, $f_{t}$ is external remittances, $p o_{t}$ is price of optimizing household consumption, $p f_{t}$ is price of formal products, $i_{t}$ is investment, $\tau_{k}$ and $\tau_{t}$ are the level of taxes on capital and labor.

The parameters $\beta, \theta, \psi_{o c}$, and $\psi_{o n c}$, the household's discount factor, the population's growth rate, and the utility weight of leisure of skilled and non-skilled labor. Moreover, with $\delta$ being the rate of depreciation, capital evolves over time in the following way:

$$
k_{t}=(1-\delta) \frac{k_{t-1}}{\theta}+i_{t}
$$

The labor market for skilled group of consumers is determined by ${ }^{7}$ :

$$
\frac{c o_{t}}{p p o c-n o c_{t}}=\frac{\left(1-\tau_{t}\right) w o c_{t}}{\psi_{o c} p o_{t}}
$$

The labor market for the unskilled group is determined by:

$$
\frac{c o_{t}}{{\text { pponc }- \text { nonc }_{t}}_{t}}=\frac{\left(1-\tau_{t}\right) \text { wonc }_{t}}{\psi_{\text {onc }} \text { pot }}
$$

\footnotetext{
${ }^{7}$ Lowercase letters refer to relative prices, expressed in terms of $P$.
} 
Further, the Euler equation is:

$$
\frac{E_{t}\left(c o_{t+1}\right)}{c o_{t}}=E_{t}\left(\beta \frac{p f_{t+1}}{p f_{t}} \frac{p o_{t}}{p o_{t+1}}\left(\left(1-\tau_{k}\right) \frac{r_{t+1}}{p y_{t+1}}+1-\delta\right)\right)
$$

The budget constraint can be expressed as:

$$
\left(1-\tau_{k}\right) \frac{r_{t} k_{t-1}}{\theta}+\left(1-\tau_{t}\right)\left(w_{o c} n o c_{t}+w_{o n c} n o n c_{t}\right)+e r_{t} f_{t}-p o_{t} c o_{t}-p f_{t}\left(k_{t}-\frac{(1-\delta) k_{t-1}}{\theta}\right)=0
$$

and the dynamics of capital become:

$$
k_{t}=(1-\delta) \frac{k_{t-1}}{\theta}+i_{t}
$$

\subsection{Households Facing Liquidity Constraints}

The decision for the second group of households will be to maximize its utility function at time $t:$

$$
M a x_{c r, n r c, n r b c} U=\operatorname{lncr}_{t}+\psi_{r c} \ln \left(p p r c-n r c_{t}\right)+\psi_{r n c} \ln \left(p p r n c-n r n c_{t}\right),
$$

subject to

$$
\text { wrc }_{t} n r c_{t}+\text { wrnc }_{t} n e n c_{t}+\operatorname{transr}_{t}=\operatorname{pr}_{T} c r_{t}
$$

where $c r_{t}$ is liquidity constrained household consumption, $p p r c_{t}$ and $p p r n c_{t}$ are fraction of agents skilled and non-skilled, $n r c_{t}$ and $n r n c_{t}$ are employment of skilled and non-skilled, $w r c_{t}$ and $w r n c_{t}$ are wage of skilled and non-skilled, transr $_{t}$ are transfers given by the government, and $p r_{t}$ is the price of liquidity constrained household consumption. Parameters $\psi_{o c}$ and $\psi_{\text {onc }}$ are the utility weight of leisure of skilled and non-skilled.

The labor market is determined by:

$$
\frac{c r_{t}}{p p r c-n r c_{t}}=\frac{w r c_{t}}{\psi_{r c} p r_{t}}
$$




$$
\frac{c r_{t}}{p p r n c-n r n c_{t}}=\frac{w r n c_{t}}{\psi_{r n c} p r_{t}}
$$

and the budget constraint:

$$
w r c_{t} n r c_{t}+w_{r n c} n r n c_{t}+\operatorname{transr}_{t}=\operatorname{pr}_{t} c r_{t}
$$

\subsection{Formality vs. Informality Decision of Non-Skilled Labor}

While skilled agents only participate in the formal sector, non-skilled workers have to decide whether to offer their labor in the formal or informal sector. Assuming that households maximize their income subject to the substitution constraint, we model this decision with a CET utility function. Following the Harris-Todaro model, we assume worker's decision to be on their expected income, which depends, in the formal market, on wage and the probability of being employed. Thus, non-skilled workers choose between joining the formal market (a market with unemployment and a limited chance of being hired) and the informal market, where they can be employed, according to the equilibrium price in this market. Optimizing households offer non-skilled labor according to:

$$
\text { nonc }_{t}=\left(\text { nonc }_{t}+u o_{t}\right)+\text { nonci }_{t},
$$

where the term in brakets is the participation in the formal market, noncf $f_{t}$ are non-skilled workers in the formal market, $u o_{t}$ is unemployment, and nonci $i_{t}$ are non-skilled workers in the informal market. For optimizing households, their path of expansion and aggregation status condition are:

$$
\begin{aligned}
& \frac{\text { nonc }_{t}+u o_{t}}{\text { nonci }_{t}}=\left(\text { probeo }_{t} \frac{\text { wonc }_{t}}{\text { wonci }_{t}} \frac{1-\omega_{o}}{\omega_{o}}\right)^{-\sigma_{o}}, \\
& \text { wonc }_{t} \text { nonc }_{t}=\text { wonc }_{t} \text { nonc } f_{t}+\text { wonci }_{t} \text { nonci }_{t} \text {, }
\end{aligned}
$$

where probeot $_{t}$ is the probability of being hired, wonc $f_{t}$ and wonci $_{t}$ are wages earned in formal and informal markets. Parameters $\omega_{o}$ and $\sigma_{o}$ are, respectively, the utility weight of formal 
market and elasticity of substitution. Formal wage evolves over time in the following way:

$$
\text { wonc }_{t}=\text { wonc }_{t-1} \text {, }
$$

and the probability of being hired in the formal market is determined by:

$$
\text { probeo }_{t}=\frac{\text { noncf }}{\text { nonc } f_{t}+u o_{t}} \text {. }
$$

The respective functions for households facing liquidity constraints are

$$
\begin{aligned}
& n r n c_{t}=\left(\operatorname{nonr}_{t}+u r_{t}\right)+n r n c i_{t}, \\
& \frac{n r n c f_{t}+u r_{t}}{n r n c i_{t}}=\left(\text { prober }_{t} \frac{w r n c f_{t}}{\text { wrncit }_{t}} \frac{1-\omega_{r}}{\omega_{r}}\right)^{-\sigma_{r}} \\
& w_{r n c} n o n c_{t}=w_{r n c} f_{t} n r n c f_{t}+\text { wrnci }_{t} n r n c i_{t}, \\
& w r n c f_{t}=w r n c f_{t-1},
\end{aligned}
$$

and

$$
\operatorname{prober}_{t}=\frac{n r n c f_{t}}{n r n c f_{t}+u r_{t}}
$$

where $n r n c f_{t}$ are non-skilled workers in the formal market, $n r n c i_{t}$ are non-skilled workers in the informal market, $u r_{t}$ is unemployment, rrober $_{t}$ is the probability of being hired, wonc $f_{t}$ and wonci $_{t}$ are wages earned in formal and informal markets. Parameters $\omega$ and $\sigma$ are, respectively, the utility weight of formal market and elasticity of substitution.

\subsection{Aggregating Household Consumption}

Aggregated consumption by the optimizing households is composed of consumption goods in the formal and the informal sector. The aggregation of all goods is represented by a CES function, given the substitutability between both types of consumption. As a result, we find the following relationships: 


$$
\begin{gathered}
c o_{t}=B_{c o}\left(\omega_{c o} c o f_{t}^{\frac{\sigma_{c o}-1}{\sigma_{c o}}}+\left(1-\omega_{c o}\right) c o i_{t}^{\frac{\sigma_{c o}-1}{\sigma_{c o}}}\right)^{\frac{\sigma_{c o}}{\sigma_{c o}-1}} \\
\frac{c o f_{t}}{c o i_{t}}=\left(\frac{p f_{t}}{p i_{t}} \frac{1-\omega_{c o}}{\omega_{c o}}\right)^{-\sigma_{c o}}
\end{gathered}
$$

and

$$
p o_{t} c o_{t}=p f_{t} c o f_{t}+p i_{t} c o i_{t} .
$$

$c o f_{t}$ and $\mathrm{coi}_{t}$ are consumption in the formal and the informal sector. $p f_{t}$ and $p i_{t}$ are their respective prices. $B_{c o}$ is a scale parameter, $\omega_{c o}$ is the utility weight of formal market and $\sigma_{c o}$ is the elasticity of substitution. For the constrained households, the respective equations become:

$$
\begin{gathered}
c r_{t}=B_{c r}\left(\omega_{c r} c r f_{t}^{\frac{\sigma_{c r}-1}{\sigma_{c r}}}+\left(1-\omega_{c r}\right) c r i_{t}^{\frac{\sigma_{c r}-1}{\sigma_{c r}}}\right)^{\frac{\sigma_{c r}}{\sigma_{c r}-1}} \\
\frac{c r f_{t}}{c r i_{t}}=\left(\frac{p f_{t}}{p i_{t}} \frac{1-\omega_{c r}}{\omega_{c r}}\right)^{-\sigma_{c r}}
\end{gathered}
$$

and

$$
p r_{t} c r_{t}=p y_{t} c r f_{t}+p i_{t} c r i_{t}
$$

\subsection{Production}

Following the work of Vasco and Yang (2010), we consider two sectors -the formal and the informal- producing different types of goods, which are sold at different prices. While the formal sector employs capital as a factor of production, the informal sector does not.

\subsubsection{The Formal Sector}

For the formal sector, we assume a production function with three distinct features: First, labor and capital are aggregated by a Cobb-Douglas function. Second, skilled and unskilled labor combine in a CES-type function. Third, skilled and unskilled labor aggregate, coming from both household types. Essentially, this means that labor from both types of households are not perfect substitutes (which may be explained by differences in education or alimentation, for 
instance). With respect to our first feature, production states:

$$
Y F_{t}=K_{t-1}^{\alpha}\left(z f_{t} L_{t} n f_{t}\right)^{1-\alpha}
$$

where $Y F_{t}$ is production in the formal sector, $K_{t-1}$ is capital, $n f_{t}$ is the work demanded, and $z f_{t}$ is the productivity. Parameter $\alpha$ is the weight of capital in the production function. Minimizing costs with respect to $Y$ leads to:

$$
\alpha K_{t-1}^{\alpha}\left(z f_{t} L_{t} n f_{t}\right)^{1-\alpha}=\frac{r_{t}}{p y_{t}}
$$

and

$$
(1-\alpha) K_{t-1}^{\alpha} z f_{t}^{1-\alpha}\left(L_{t} n f_{t}\right)^{-\alpha}=\frac{w f_{t}}{p y_{t}}
$$

Expressing the above equations in per capita terms, deflated by the IPC, gives:

$$
\alpha k_{t-1}^{\alpha-1} \theta^{1-\alpha}\left(z f_{t} n f_{t}\right)^{1-\alpha}=\frac{r_{t}}{p y_{t}}
$$

and

$$
(1-\alpha) k_{t-1}^{\alpha} \theta^{-\alpha} z f_{t}^{1-\alpha} n f_{t}^{-\alpha}=\frac{w f_{t}}{p y_{t}} .
$$

The production function in per capita terms becomes:

$$
y f_{t}=\left(\frac{k_{t-1}}{\theta}\right)^{\alpha}\left(z f_{t} n f_{t}\right)^{1-\alpha} .
$$

Aggregated labor in the formal sector consists of skilled and unskilled labor, combined in a CES-type setting. Minimizing costs leads to the following equations:

$$
\begin{gathered}
n f_{t}=B_{p f}\left(\omega_{p f} n f c_{t}^{\frac{\sigma_{p f}-1}{\sigma_{p f}}}+\left(1-\omega_{p f}\right) n f n c_{t}^{\frac{\sigma_{p f}-1}{\sigma_{p f}}}\right)^{\frac{\sigma_{p f}}{\sigma_{p f}-1}} \\
\frac{n f c_{t}}{n f n f_{t}}=\left(\frac{w f c_{t}}{w f n c_{t}} \frac{1-\omega_{p f}}{\omega_{p f}}\right)^{\sigma_{p f}}
\end{gathered}
$$


and

$$
w f_{t} n f_{t}=w f c_{t} n f c_{t}+w f n c_{t} w f n c_{i}
$$

$B_{p f}$ is a scale parameter, $\omega_{p f}$ is the utility weight of skilled labor and $\sigma_{p f}$ is the elasticity of substitution. Skilled and unskilled work in the formal sector are the result of adding optimizing and liquidity-constrained households. As noted before, both distinct types of labor are not perfect substitutes. The distinction can be explained by various aspects, for instance differences in training, education, or general living conditions (health, food, etc.). Companies minimize labor costs of both skilled and unskilled labor, given the aggregation constraint of household work. The resulting equations for labor in the formal sector then are:

$$
\begin{gathered}
n f c_{t}=B_{f c}\left(\omega_{f c} n o c_{t}^{\frac{\sigma_{f c}-1}{\sigma_{f c}}}+\left(1-\omega_{f c}\right) n r c_{t}^{\frac{\sigma_{f c}-1}{\sigma_{f c}}}\right)^{\frac{\sigma_{f c}}{\sigma_{f c}-1}} \\
\frac{n o c_{t}}{n r c_{t}}=\left(\frac{w o c_{t}}{w r c_{t}} \frac{1-\omega_{f c}}{\omega_{f c}}\right)^{-\sigma_{f c}}, \\
w f c_{t} n f c_{t}\left(1-\tau_{c}\right)=w o c_{t} n o c_{t}+w r c_{t} w r c_{i}
\end{gathered}
$$

and for unskilled formal sector labor:

$$
\begin{gathered}
n f n c_{t}=B_{f n}\left(\omega_{f n} n o n c f_{t}^{\frac{\sigma_{f n}-1}{\sigma_{f n}}}+\left(1-\omega_{f n}\right) n r n c f_{t}^{\frac{\sigma_{f n}-1}{\sigma_{f n}}}\right)^{\frac{\sigma_{f n}}{\sigma_{f n}-1}} \\
\frac{n o n c f_{t}}{n r n c f_{t}}=\left(\frac{w o n c f_{t}}{\text { wrncf }_{t}} \frac{1-\omega_{f n}}{\omega_{f n}}\right)^{-\sigma_{f n}},
\end{gathered}
$$

and

$$
w f n c_{t} n f n c_{t}\left(1-\tau_{c}\right)=w_{o n c} f_{t} n o n c f_{t}+w r n c f_{t} w r n c f_{i} \text {. }
$$

$B_{f c}$ and $B_{f n}$ are scale parameters, $\omega_{f c}$ and $\omega_{f n}$ are, respectively, the utility weight of optimizing households, whilst $\sigma_{f c}$ and $\sigma_{f n}$ are the elasticity of substitution of each function. 


\subsubsection{The Informal Sector}

We assume the production function in the informal sector (in per capita terms) to be:

$$
y i_{t}=z i_{t} n i_{t}
$$

The optimality condition becomes:

$$
z i_{t}=\frac{w i_{t}}{p i_{t}}
$$

Then, the equilibrium in the informal sector is given by:

$$
y i_{t}=\operatorname{coi}_{t}+\operatorname{cri}_{t} .
$$

Now, informal work is also the aggregation (using a CES function) of informal labor from optimizing and constrained households. The optimality conditions for both types of work are summarized in the following equations:

$$
\begin{aligned}
& n i_{t}=B_{p i}\left(\omega_{p i} n o n c i_{t}^{\frac{\sigma_{p i}-1}{\sigma_{p i}}}+\left(1-\omega_{p i}\right) n r n c i_{t}^{\frac{\sigma_{p i}-1}{\sigma_{p i}}}\right)^{\frac{\sigma_{p i}}{\sigma_{p i}-1}}, \\
& \frac{\text { nonci }_{t}}{\text { nrnci }_{t}}=\left(\frac{\text { wonci }_{t}}{\text { wrnci }_{t}} \frac{1-\omega_{p i}}{\omega_{p i}}\right)^{-\sigma_{p i}}
\end{aligned}
$$

and

$$
w f n c_{t} n f n c_{t}=w_{o n c} f_{t} n o n c f_{t}+w r n c f_{t} w r n c f_{i},
$$

where the parameters $B_{p i}, \omega_{p i}$ and $\sigma_{p i}$ are, respectively, a scale parameter, the utility weight of optimizing household, and the elasticity of substitution.

\subsection{International Trade}

We assume the existence an international sector, catering to the demand for domestic and imported goods. The demand for exports depends on foreign traders, who can purchase goods from the domestic country or from other sources. Export supply is modeled based on the optimal decision-making of entrepreneurs, who can channel their productive resources towards domestic 
or international markets.

\subsubsection{The Demand For Imports}

Retailers minimize their spending, given that imported and domestic goods are not perfect substitutes. Therefore, we model the aggregation of these assets by a CES function, and the cost minimization process of retailers results in the following relationships:

$$
\begin{gathered}
c o f_{t}+c r f_{t}+g_{t}+i_{t}=B_{m}\left(\omega_{m} m_{t}^{\frac{\sigma_{m}-1}{\sigma_{m}}}+\left(1-\omega_{m}\right) d_{t}^{\frac{\sigma_{m}-1}{\sigma_{m}}}\right)^{\frac{\sigma_{m}}{\sigma_{m}-1}} \\
\frac{m_{t}}{d_{t}}=\left(\frac{p m_{t}}{p d_{t}} \frac{1-\omega_{m}}{\omega_{m}}\right)^{-\sigma_{m}}
\end{gathered}
$$

and

$$
p f_{t}\left(\operatorname{cof}_{t}+\operatorname{cr} f_{t}+g_{t}+i_{t}\right)=(1+i v a)\left(p m_{t} m_{t}+p d_{t} d_{i}\right)
$$

The domestic price of imports is given by:

$$
p m_{t}=\operatorname{pwm}_{t} e r_{t}(1+\operatorname{aran})
$$

where $g_{t}$ is government spending, $m_{t}$ and $p m_{t}$ are imports and its price, $d_{t}$ and $p d_{t}$ are domestic demand and its price, $p w m_{t}$ is the international price of imported goods, and $e r_{t}$ is the nominal exchange rate. $B_{m}$ is a scale parameter, $\omega_{m}$ is the utility weight of imported goods, $\sigma_{p i}$ is the elasticity of substitution, iva is a value added tax, and aran is an import tariff.

\subsubsection{The Supply Of Exports}

Input use determines the production possibility frontier of entrepreneurs, who can use their goods for Exports or domestic sales. Given this production limit (which is modeled by a CET function), entrepreneurs maximize their profit by choosing the optimal mix of exports and domestic sales. The resulting equations are:

$$
y f_{t}=B_{e}\left(\omega_{e} x_{t}^{\frac{\sigma_{e}-1}{\sigma_{e}}}+\left(1-\omega_{e}\right) d_{t}^{\frac{\sigma_{e}-1}{\sigma_{e}}}\right)^{\frac{\sigma_{e}}{\sigma_{e}-1}}
$$




$$
\frac{x_{t}}{d_{t}}=\left(\frac{p x_{t}}{p d_{t}} \frac{1-\omega_{e}}{\omega_{e}}\right)^{-\sigma_{e}}
$$

and

$$
p f_{t} y f_{t}=\left(p x_{t} x_{t}+p d_{t} d_{t}\right)
$$

The domestic price of exports then becomes:

$$
p x_{t}=p w x_{t} e r_{t}
$$

where $x_{t}$ and $p x_{t}$ are exports and its price and $p w x_{t}$ is the international price of export goods. $B_{e}$ is a scale parameter, $\omega_{e}$ is the utility weight of exported goods, $\sigma_{e}$ is the elasticity of substitution.

\subsubsection{The Demand For Exports}

The country's exports are not perfect substitutes for goods of other origin. Thus, the international buyer minimizes his expenditure, given the CES aggregation function linking country purchases and purchases from other suppliers. The equations governing this behavior are:

$$
x t_{t}=B_{x}\left(\omega_{x} x_{t}^{\frac{\sigma_{x}-1}{\sigma_{x}}}+\left(1-\omega_{x}\right) x x_{t}^{\frac{\sigma_{x}-1}{\sigma_{x}}}\right)^{\frac{\sigma_{x}}{\sigma_{x}-1}}
$$

and

$$
\frac{x_{t}}{x x_{t}}=\left(\frac{p w x_{t}}{p w_{t}} \frac{1-\omega_{x}}{\omega_{x}}\right)^{-\sigma_{x}}
$$

where $x x_{t}$ and $p w_{t}$ are purchases from other suppliers and its price. $B_{x}$ is a scale parameter, $\omega_{x}$ is the utility weight of country purchases, $\sigma_{x}$ is the elasticity of substitution.

\subsection{Closed Macroeconomy}

Equality of savings and investment is guaranteed in the above approach, as savings mare are equal to total investment in the economy. The government's budgetary imbalance is financed by external borrowing $s_{t}$ and external interest rates $r i_{t}$ : 


$$
\begin{aligned}
& s_{t} e r_{t}=\frac{s_{t-1}}{\theta} \text { ri }_{t} e r_{t}+p f_{t} g_{t}+\operatorname{trans}_{t}-\tau_{k} \frac{r_{t} k_{t-1}}{\theta}+\tau_{t}\left(\text { woc }_{t} n o c_{t}+\text { wonc }_{t} n o n c_{t}\right) \\
& \quad+\tau_{c}\left(w f c_{t} n f c_{t}+w f n c_{t} n f n c_{t}\right)-i v a \frac{p f_{t}\left(\operatorname{cof}_{t}+\operatorname{crf}_{t}+g_{t}+i_{t}\right)}{1+i v a}-\operatorname{aran}\left(\text { pwm }_{t} m_{t} e r_{t}\right) .
\end{aligned}
$$

As soon as the external market closes, the exchange rate adjusts to equalize Current and Capital Account (balance of payments): ${ }^{8}$

$$
\text { walras }_{t}=p w x_{t} x_{t}+f_{t}+\left(s_{t}-\frac{s_{t-1}}{\theta} r i_{t}\right)-p w m_{t} m_{t} .
$$

GDP is defined as:

$$
g d p_{t}=p f_{t}\left(c o f_{t}+c r f_{t}+g_{t}+i_{t}\right)+p i_{t}\left(c o i_{t}+c r i_{t}\right)+p x_{t} x_{t}-\frac{p m_{t} m_{t}}{1+\operatorname{aran}} .
$$

The government determines public spending in order to maintain a targeted debt level:

$$
\frac{s_{t} e r_{t}}{g d p_{t}}=\text { target }
$$

The consumer price index $\left(c p i_{t}\right)$ is defined as:

$$
\frac{p f_{t}\left(c o f_{t}+c r f_{t}\right)+p i_{t}\left(c o i_{t}+c r i_{t}\right)}{\operatorname{cof} f_{t}+c r f_{t}+c o i_{t}+c r i_{t}}=c p i_{t}=1 .
$$

\section{Simulations}

In this paper, we postulate that the government needs to dedicate resources to constrained households in an attempt to generate income redistribution through appropriate policies; specifically, the government aims to raise transfers to these households by 1 percent. From the perspective of the steady-state equilibrium, we assume public finances to be in their long run equilibrium and thus we neither consider the option of raising public debt nor printing money as an alternative

\footnotetext{
${ }^{8}$ Technically, this equation is redundant: the budgetary constraints of the remaining agents in the system and the fact that markets are in equilibrium ensure this equation to remain balanced as well. However, it includes the "Walras" variable to ensure compliance with this condition (known as Walras' Law) in the system. Its value must be zero at any point of time.
} 
to reducing the deficit. The latter element follows directly from not including monetary relations in the model. Thus, in order to finance additional transfer payments, the government must cut spending or increase revenue through the use of various taxes.

With this in mind, we initially consider four possible scenarios: an offsetting reduction in public spending, increasing taxes on capital, raising taxes on labor, and an increase in social security contributions by companies. Traditionally, these types of models consider shocks to productivity, which leads us to include an additional option, in which the increased transfer payments are financed by productivity of companies in the formal sector, as a point of comparison to the previous scenarios. Our results are compared to findings from Alm and López (2002), Agénor and Dc (2003),Ulyssea (2010), Bosch and Esteban-Pretel (2012), and Hamann and Mejía (2011), among others. Our simulations display the following relationships ${ }^{9}$ :

GDP and capital: financing transfer payments with higher taxes or lower government spending yields a negative response in the behavior of both GDP and capital. As expected, the increase in taxes on capital causes a collapse in capital used, but only in the formal sector of the economy. Financing transfer payments with higher productivity on the other hand leads to an increase of both aggregate production and capital, where the latter effect results from positive changes in investment flows (see figure 1).

Companies: if financing occurs through taxes, the level of production diminishes in formal sector companies - a result that Bosch and Esteban-Pretel (2012) focuses on. The situation is comparable for informal sector companies, except for the case when financing happens through an increase in social security contributions by the formal sector. This finding is consistent with Ulyssea (2010).

\section{Insert Figure:The Effects from Increased Transfer Payments on GDP and Capital.}

Labor hired by companies displays a similar behavior, as it only increases in informal companies when the source of funding is an increase in social security taxes. In this case the cost

\footnotetext{
${ }^{9}$ See appendix one and two about data calibration and parameters used.
} 
is borne by the formal sector, as opposed to improvements in productivity, in which case there would be a positive effect through job creation in the formal sector (see figure 2).

\section{Insert Figure:The Effects from Increased Transfer Payments on Companies}

The total labor market:Within this framework, the employment rate falls with formal companies hiring less after facing an increased tax burden. At the same time, households with liquidity constraints (informals) decrease their participation rate as a consequence from higher after-tax incomes. This fall in employment turns out to be greater in size than the newly created employment, which in turn diminishes the unemployment rate among those households. In this context, public handouts only create problems in the formal sector as the labor market in the informal sector restructures itself with people becoming inactive after receiving transfer payments. As for the utility-maximizing households (formal sector), both scenarios of financing transfer payments with taxes on capital or on social security payments carry strong negative effects. These results are in line from Bosch and Esteban-Pretel (2012), who finds that government interventions in the labor market generate a reallocation of workers across the formal and informal sector (see figure 3).

Insert Figure:The Effects from Increased Transfer Payments on the Labor Market

Informality and distribution:The fall in the level of informal employment is related to a relatively bigger job creation in the formal sector. Financing transfer payments by higher taxes on labor would decrease informality, where the degree of informality of companies reflects the relative size of production between sectors. However, the main consequence of the increase in transfers is the improvement in income distribution, as households with restrictions are better off (see figure 4).

Insert Figure:The Effects from Increased Transfer Payments on Informality and

\section{Distribution}




\section{Conclusions}

The goal of this article is to evaluate the impact of fiscal instruments on two fundamental characteristics of middle income countries, such as Colombia: the persistent income inequality within the society and the substantial degree of informality.

Increased transfer payments to households with lower incomes, which in this case translates to households facing liquidity constraints, have a positive effect on income distribution. However, in order to finance these additional payments, one has to tolerate higher taxes or a reduction in other areas of public spending - both measurements which have a negative effect on productivity in the formal sector, on GDP, and on investment. In consequence, this translates to less total income. Through this mechanism one achieves a better distribution of less wealth.

Financing transfers with increases in taxes either on social security contributions or on capital translates to an increased degree of informality, whereas raising taxes on labor and a reduction in public spending have the opposite effect. These results are similar to what we observe in the unemployment rate, which increases when taxes on social security and capital are raised, but drops when government spending is reduced or when taxes on labor are raised.

Finally, it is important to highlight the results from the scenario of an increase in productivity in the formal sector. When the economy is capable of raising productivity, investment and formal sector productivity rises, which in turn translates to higher growth, tax revenues, employment, transfer payments, a lesser degree of informality, higher incomes, and a better income distribution within the population. 


\section{References}

Agénor P.; Bank, T. W.; and W. Dc (2003). "The Mini-Integrated Macroeconomic Model for Poverty Analysis". In: A Framework for Analyzing the Unemployment and Poverty Effects of Fiscal and Labor Market Reforms, 1-82.

Alm, James and Hugo López (2002). "Impuestos sobre la nómina en Colombia". In: Documentos de Trabajo, Fedesarrollo.

Andolfatto, D. (1996). "Business Cycles and Labor-Market Search". In: American Economic Review 86, pp. 112-132.

Bosch, M. and J. Esteban-Pretel (2012). "Job creation and job destruction in the presence of informal markets". In: Journal of Development Economics 96.2, pp. 270-286.

Castells M., Portes Alejandro and Laurent. Belton (1989). The informal Economy: Studies in Advanced and less Developed Countries. Ed. by editor. Johns Hopkins University Pres:Baltimore.

Christoffel, K. and T. Linzert (2010). "The Role of Real Wage Rigidity and Labor Market Frictions for Inflation Persistence". In: Journal of Money, Credit and Banking 42, pp. 143546.

Competitividad, Consejo Privado de (2012). Informe Nacional de Competitividad. Tech. rep. Consejo Privado de Competitividad.

Cook, D. (2005). "Dual Labor Markets and Business Cycles". In: working paper 852, pp. 1-26.

Crédito Público, Ministerio de Hacienda y (2011). Marco fiscal de mediano plazo 2011. Tech. rep. Ministerio de Hacienda y Crédito Público.

Haan W.; Ramey, G. den and J. Watson (2000). "Job Destruction and Propagation of Shocks". In: American Economic Review 90, pp. 482-98.

Hamann, Franz and Luis Fernando Mejía (2011). "Formalizando la informalidad empresarial en Colombia". In: Borradores de Economía No 676, Banco de la República.

ILO (1972). "Employment, Income and Equality: A Strategy for Increasing Productivity in Kenya". In: International Labour Organization: Geneva.

Krause, M. U. and T. A. Lubik (2007). "The (Ir)Relevance of Real Wage Rigidity in the NewKeynesian Model with Search Frictions". In: Journal of Monetary Economics 54, pp. 706-27.

Merz, M. (1995). "Search in the Labor Market and the Real Business Cycle". In: Journal of Monetary Economics 36, pp. 269-300. 
Perry Guillermo; Fajnzylber, Pablo; Maloney William F.; Arias Omar; Mason Andrew and Jaime Saavedra-Chanduvi (2007). Informality: exit and exclusion. Tech. rep. World Bank.

Pratap, Sangeeta and Erwan Quintin (2006). "The informal sector in Developing Countries: Output, Assets and Employment". In: Research paper No 130, United Nations University, World Institute for Development Economic Research UNU-WIDER, November.

Satchi, M. and J.r Temple (2009). "Review of Economic Dynamics Labor markets and productivity in developing countries". In: Review of Economic Dynamics 12.1, pp. 183-204.

Schneider, F. and D. H. Enste (2000). "Shadow economies: size, causes and consequences". In: Journal of Economic literature 38.1, pp. 77-114.

Ulyssea, G. (2010). "Regulation of entry, labor market institutions and the informal sector". In: Journal of Development Economics 91.1, pp. 87-99.

Vasco Gabriel; Levine, Paul; Pearlman Joseph; and Bo Yang (2010). "An Estimated DSGE Model of the Indian Economy". In: NIPE Working Papers, NIPE - Universidade do Minho 29.

Walsh, C. E (2005). "Labor Market Search, Sticky Prices, and Interest Rate policies". In: Review of Economic Dynamics 8, pp. 829-49. 


\begin{tabular}{||c|c||c|c||c|c||}
\hline \multicolumn{7}{|c|}{ Appendix 1 } \\
\hline \multicolumn{1}{|c|}{} & \multicolumn{5}{|c||}{ Variables } \\
\hline noc & 0.0832 & nrncf & 0.0612 & $d$ & 6.4879 \\
\hline nonc & 0.1798 & nrnci & 0.0853 & $p m$ & 1.0000 \\
\hline co & 5.0214 & wrncf & 4.5328 & $p d$ & 1.0000 \\
\hline$i$ & 2.5194 & wrnci & 3.4430 & $x$ & 1.6220 \\
\hline$k$ & 20.8164 & $c o f$ & 4.2240 & $p x$ & 1.0000 \\
\hline woc & 23.5870 & $c o i$ & 0.7975 & $p w x$ & 1.0000 \\
\hline wonc & 8.7921 & $p f$ & 1.0000 & $x x$ & 162.2048 \\
\hline po & 1.0000 & $p i$ & 1.0000 & $s$ & 2.6291 \\
\hline$r$ & 0.2037 & $c r f$ & 1.1681 & gdp & 10.1160 \\
\hline$f$ & 0.4879 & $c r i$ & 0.1960 & $i p c$ & 1.0000 \\
\hline er & 1.0000 & $y f$ & 8.1099 & employment & 0.4009 \\
\hline nrc & 0.0060 & $n f$ & 0.2478 & ginfn & 0.3817 \\
\hline nrnc & 0.1749 & $p y$ & 1.0000 & ingo & 7.5409 \\
\hline cr & 1.3641 & $w f$ & 15.8975 & ingr & 1.3641 \\
\hline wrc & 4.2527 & $z f$ & 12.2831 & distr & 0.1532 \\
\hline wrnc & 3.2659 & $n f c$ & 0.0892 & transr & 0.7674 \\
\hline pr & 1.0000 & $n f n c$ & 0.1586 & $\tau_{k}$ & 0.1245 \\
\hline noncf & 0.0974 & $w f c$ & 27.8997 & $\tau_{t}$ & 0.0401 \\
\hline nonci & 0.0678 & $w f n c$ & 9.1446 & $\tau_{c}$ & 0.2012 \\
\hline uo & 0.0147 & $y i$ & 0.9934 & iva & 0.1041 \\
\hline ur & 0.0284 & $n i$ & 0.1530 & xt & 163.8269 \\
\hline probeo & 0.8690 & $w i$ & 6.4922 & walras & 0.0000 \\
\hline prober & 0.6833 & $z i$ & 6.4922 & aran & 0.0547 \\
\hline woncf & 9.0483 & $g$ & 1.6394 & ing & 8.9050 \\
\hline wonci & 10.3293 & $m$ & 2.1626 & ginfy & 0.1091 \\
\hline
\end{tabular}

Table 1: Source: Values are calculated from National Accounts and GEIH published by DANE, Own Elaboration. 


\begin{tabular}{|c|c|c|c|c|c|}
\hline \multicolumn{6}{|c|}{ Appendix 2} \\
\hline \multicolumn{6}{|c|}{ Parameters } \\
\hline$\beta$ & 0.9326 & $\sigma_{c o}$ & 1.5000 & $\sigma_{m}$ & 1.4000 \\
\hline ppoc & 0.1116 & $B_{c o}$ & 1.6613 & $B_{m}$ & 2.0044 \\
\hline$\psi_{o c}$ & 0.1279 & $\omega_{c o}$ & 0.7524 & $\omega_{m}$ & 0.3133 \\
\hline$\psi_{\text {onc }}$ & 0.2229 & $\sigma_{c r}$ & 1.5000 & $\operatorname{aran} 0$ & 0.0547 \\
\hline pponc & 0.3124 & $B_{c r}$ & 1.6267 & pwm & 0.9482 \\
\hline$\tau_{k 0}$ & 0.1245 & $\omega_{c r}$ & 0.7668 & $\sigma_{e}$ & -1.5000 \\
\hline$\tau_{t 0}$ & 0.0401 & $\alpha$ & 0.5142 & $B_{e}$ & 2.3263 \\
\hline$\tau_{c 0}$ & 0.2012 & $\sigma_{p f}$ & 0.7000 & $\omega_{e}$ & 0.7159 \\
\hline$\theta$ & 1.0170 & $B_{p f}$ & 2.2100 & $x t 0$ & 163.8269 \\
\hline$\delta$ & 0.1061 & $\omega_{p f}$ & 0.5729 & $p w$ & 1.0000 \\
\hline$\psi_{r c}$ & 0.0216 & $\sigma_{f c}$ & 0.7000 & $\sigma_{x}$ & 1.5000 \\
\hline$\psi_{r n c}$ & 0.3887 & $B_{f c}$ & 1.0941 & $B_{x}$ & 1.1232 \\
\hline pprc & 0.0129 & $\omega_{f c}$ & 0.9958 & $\omega_{x}$ & 0.0444 \\
\hline pprnc & 0.3372 & $\sigma_{f n}$ & 0.7000 & target & 0.2599 \\
\hline transr 0 & 0.7674 & $B_{f n}$ & 1.8057 & $r i$ & 1.0400 \\
\hline$\sigma_{o}$ & -2.0000 & $\omega_{f n}$ & 0.7947 & $f 0$ & 0.4879 \\
\hline$g 0$ & 1.6394 & $\sigma_{p i}$ & 0.7000 & $z f 0$ & 12.2831 \\
\hline$\omega_{o}$ & 0.3718 & $B_{p i}$ & 2.1051 & $z i 0$ & 6.4922 \\
\hline$\sigma_{r}$ & -2.0000 & $\omega_{p i}$ & 0.6836 & $i p c 0$ & 1.0000 \\
\hline$\omega_{r}$ & 0.4674 & $i v a 0$ & 0.1041 & & \\
\hline
\end{tabular}

Table 2: Source: Values are calculated from National Accounts and GEIH published by DANE, Own Elaboration. 